\title{
Behaviour of precast reinforced concrete columns subjected to monotonic short-term loading
}

\author{
S. S. R. Pereira, H. Carvalho, J. V. F. Dias, V. R. Verga M. \\ Federal University of Minas Gerais, Brazil \\ ssrp@dees.ufmg.br,bermes@dees.ufmg.br,joaovfdias@ufmg.br,victor.verga.eng@gmail.com, \\ P. A. Montenegro \\ CONSTRUCT - LESE, Faculty of Engineering, University of Porto - FEUP, Portugal \\ paires@fe.up.pt
}

\begin{abstract}
This paper presents a case study on the behaviour of precast reinforced columns with non-conventional cross-section. An experimental program was developed to verify the serviceability and ultimate limit states of these columns, loaded with eccentric compression forces. In addition, results obtained through a theoretical model based on the Brazilian standard ABNT NBR 6118:2014 and a Finite Element numerical model using ANSYS software were presented. Analysis of the results showed that the proposed models satisfactorily predicted column behaviour. However, the ultimate strength of the column could not be determined due to limitations in the formulation of the theoretical model. The numerical model presented good agreement with the experimental results, both in serviceability and in ultimate limit state.
\end{abstract}

KEYwORDS. Column; Reinforced concrete; Short-term loading; Numerical modelling.

\section{OPEN ACCESS}

Citation: Pereira, S. S. R., Carvalho, H., Dias, J. V.F., Verga M., V. R., Montenegro, P. A., Behavior of precast reinforced concrete columns subjected to monotonic short-term loading, Frattura ed Integrità Strutturale, xx (2019) 242-250.

Received: 25.07.2019

Accepted: 03.09.2019

Published: 01.10.2019

Copyright: (C) 2019 This is an open access article under the terms of the CC-BY 4.0, which permits unrestricted use, distribution, and reproduction in any medium, provided the original author and source are credited.

\section{INTRODUCTION}

T wo main guidelines for the use of precast concrete in the construction industry are identified: one aiming at rationalization of the execution of concrete structures and the other for construction industrialization [1]. The ABNT NBR 9062:2017 standard [2] is the technical document governing the use of precast structural elements in Brazil. It establishes requirements for the design, execution and control of reinforced or prestressed precast concrete structures, indicating criteria for the design and construction of these structures. This standard defines a precast element as the one that has been previously concreted outside the place of permanent use of the structure, and a prefabricated element as the one that has been industrially executed, in permanent installations of a company intended for this purpose. 
The ABNT NBR 9062:2017 [2] recalls the ABNT NBR 6118:2014 [3] standard, which deals with the design of concrete structures in general. It contemplates the verification of structural elements, precast or not, with any cross-section. In addition to usual design procedures, evaluation of serviceability and ultimate limit states by means of physical model tests, performing statistically based validation or the adoption of non-linear physical analysis (for which basic hypotheses to be followed are indicated) are also permitted.

In the study of precast concrete columns, an effort of the scientific community is observed due to the great efficiency of the constructive method, reduction in the construction time and consequently in the cost of the building. However, the shapes of structural elements may be diverse in order to facilitate assembly between the elements. Because of this, the design elements cannot be covered by the conventional procedures presented in current reinforced concrete standards. Thus, it is necessary to evaluate experimentally or numerically the behaviours and resistance of columns with non-conventional crosssection. Faced with this motivation, Feng et al. (2019) [4] developed numerical simulations of the progressive collapse performance of precast reinforced concrete. Li et al. (2017) [5] numerically evaluated segmental columns under blast loads. Ghayeb et al. (2017) [6] experimentally evaluated a new type of precast concrete beam-to-column connections. Wibowo et al. (2009) [7] developed numerical models of precast reinforced concrete columns and the results were compared with field test results.

Regarding numerical modelling of concrete structures, due to the complexities in the material's behaviour, finding a suitable mathematical model that enables the prediction of structural behaviour is a challenge, requiring the use of simplifications. In the past, the development of stress-strain relationships for concrete was limited to formulations in the uniaxial and biaxial stress state. Increased use of large triaxially loaded structures, such as reactor pressure vessels, containments, damns, offshore platforms, marine tanks, etc. have led to the need for formulations of constitutive relations for concrete subjected to three-dimensional stress states.

Several authors have been engaged in the search for a realistic physical model, which would enable simulation of the linear mechanical behaviour and the nonlinear behaviour caused by plasticity and cracking. Several studies on the applicable failure criteria in a triaxial stress state available in the literature present good correlation with experimental studies and enable prediction of ultimate limit state after the occurrence of cracking. Chen and Chen $(1973,1975)$ proposed constitutive relationships representing the nonlinear behaviour of concrete submitted to monotonic loading [8,9]. Willam \& Warnke (1975) suggested an elastoplastic failure criterion based on five control parameters [10]. Ottosen (1977) proposed a failure criterion based on four parameters, considering the application of short-term monotonic loads [11]. Hsieh et al. (1982) developed an elastoplastic failure criterion with fracture based on four parameters that allow the occurrence of large-scale flow [12]. Boswell and Chen (1985) proposed a failure criterion based on eight parameters with a strength surface for the case in which concrete is considered as linear elastic with fracture or a yield surface for concrete considered elastic and perfectly plastic [13].

Currently, users of the ANSYS commercial software [14] often utilize the Willam \& Warnke (1975) [10] criterion because this model is the only one available in the material library for physically nonlinear analysis involving concrete. Studies addressing the behaviour of concrete structures have been based on this failure criterion. Barbosa and Ribeiro (1998) used different stress-strain relationships for concrete and obtained good agreement with experimental results by using this model [15]. Wolanski (2004) simulated the behaviour of reinforced and prestressed concrete slabs submitted to simple bending [16]. Queiroz et al. (2014) developed numerical models of steel and concrete composite beams with flexible connectors to evaluate the contribution of friction at the steel-concrete interface [17].

Another line involving finite element models in the ANSYS software is based on the development of new finite elements (solid and plane) using user programmable features, which allow the inclusion of new material models that are not available in the library. Lazzari et al. (2017) used these features to develop elastoplastic and viscoelastoplastic constitutive models, combined with the Ottosen (1997) failure criterion for prediction of the behaviour of reinforced and prestressed concrete [18] [19].

The present work presents a case study of a column with non-usual cross-section used in a Brazilian popular housing project of buildings with up to four floors. This project presents a system with prefabricated columns, beams and slabs that are developed in modules. For an adequate sealing of the wall sealing panels, the column presents recesses and protrusions in the section shape that provide tight connection regions along its height, resulting in an element with non-conventional shape.

These columns were analysed in three different ways. First, an experimental program was developed, comprising four tests on real-scale columns, in order to verify their behaviour both in serviceability and in ultimate limit state. Secondly, a previously developed theoretical model was applied to verify the columns behaviour in serviceability. Finally, finite element numerical models of the tested columns were developed in the commercial code ANSYS to verify their behaviour. 


\section{Experimental Program}

T $\mathrm{n}$ order to estimate the column strength in situations of combined bending and compression, an experimental program was conducted with four columns, with the same geometry and reinforcement ratio, but with different eccentricities. Experimental models were designed with rigid consoles at both ends in order to enable the application of eccentric forces. Each specimen had a total length of $3400 \mathrm{~mm}$, of which $800 \mathrm{~mm}$ were reserved to the consoles, as shown in Fig. 1.
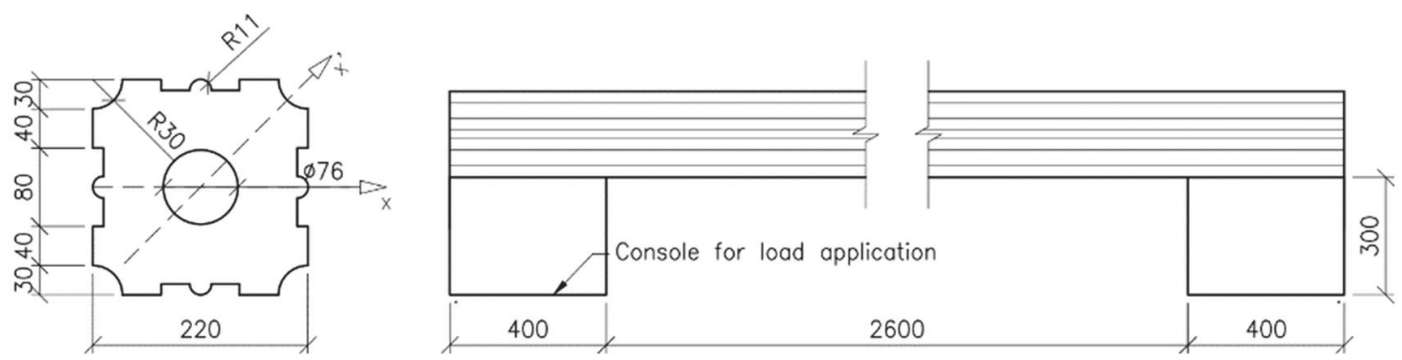

Figure 1: Column geometry and dimensions (in $\mathrm{mm}$ ).

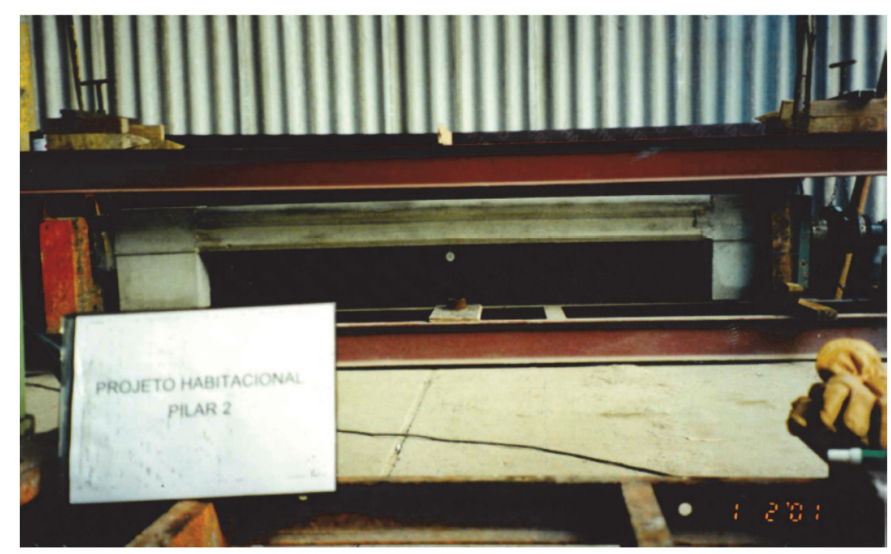

Figure 2: Column positioned for testing.

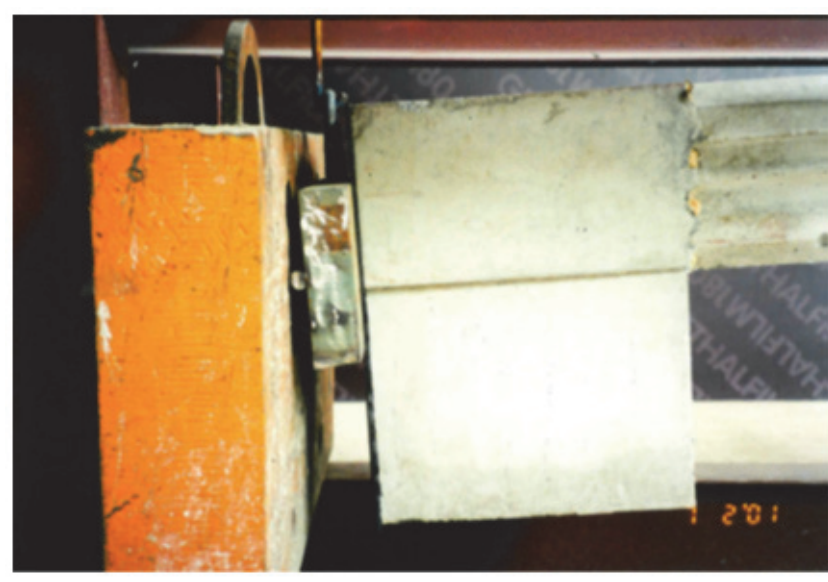

(a)

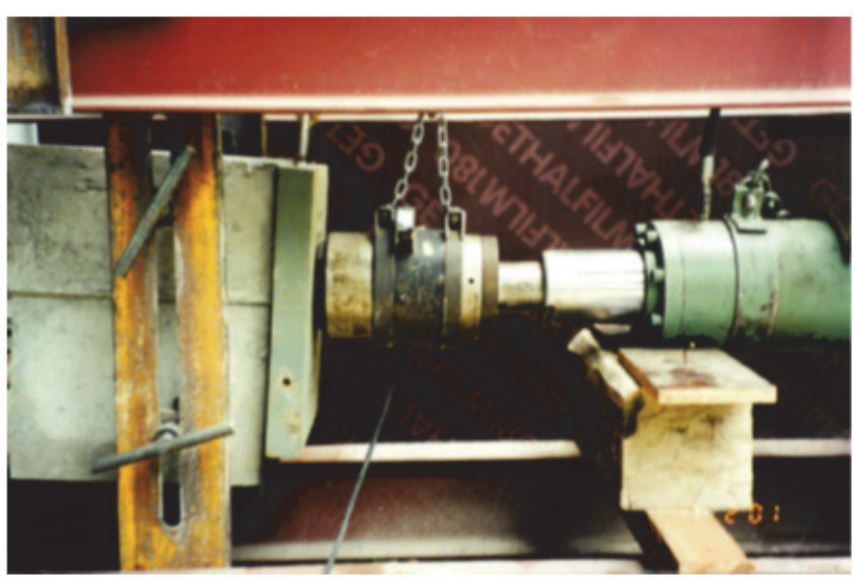

(b)

Figure 3: Test setup: (a) end supported by a reaction block and (b) hydraulic jack in the opposite end.

The cross section of the column is hollow along its entire length and its boundaries present recesses and protrusions that ensure tightness on the contact surface with sealing panels, resulting in a complex perimeter, as presented in Fig. 1. 
The concrete used in the production of the models had its strength tested at 28 days of age and its average compressive strength was $33.5 \mathrm{MPa}$. All models had four longitudinal $12.5 \mathrm{~mm}$ CA-50 reinforcement bars and $5 \mathrm{~mm}$ transverse reinforcement bars spaced every $150 \mathrm{~mm}$. Specimens were submitted to a concentrated eccentric force applied at a fixed point on the consoles to impose a combined bending and compression situation on the column. The column is simply supported on both ends, being one of them supported on a reaction block and the opposite one subjected to a point load applied by a hydraulic jack, as shown in Figs. 2 and 3.

For force application, a hydraulic jack equipped with a load cell was used, which enabled monitoring of the forces applied throughout the tests. To obtain the lateral displacements of the column, a displacement transducer was positioned at the midspan. When the column was close to rupture, the sensor was removed and displacement was measured with a tape.

Four tests were conducted with different eccentricities. Tests E1 and E2 had eccentricities of $82 \mathrm{~mm}$ and $310 \mathrm{~mm}$ in the $x$ direction (see Fig. 1) and tests E3 and E4 had eccentricities of $72 \mathrm{~mm}$ and $264 \mathrm{~mm}$ in the $x^{\prime}$ direction, rotated $45^{\circ}$ in relation to $x$ (see Fig. 1), as shown in Tab. 1.

\begin{tabular}{ccc}
\hline Test & Axis direction & Eccentricity $[\mathrm{mm}]$ \\
1 & $x$ & 82 \\
2 & $x$ & 310 \\
3 & $x^{\prime}$ & 72 \\
4 & $x^{\prime}$ & 260 \\
\hline
\end{tabular}

Table 1: Overall characteristics of the tests performed.

\title{
THEORETICAL ANALYSIS
}

\begin{abstract}
A theoretical model considering the stress-strain relationships of steel and concrete presented by the ABNT NBR 6118:2014, first presented by Pereira et al. (2013) [20] was adapted to evaluate the tested columns in serviceability. This model considers the physical nonlinearities due to rheological behaviour of concrete, such as shrinkage, creep and cracking and, not only the variations of properties over time, but also the loading history of the concrete structural element. Computationally, the structure is longitudinally divided into elements, each of which may have different physical properties, as well as different loading histories.

Several assumptions are adopted in the development of this model. First, the column cross section, the applied loads and the deformations remain in a plane. Secondly, the loading plane corresponds to an element symmetry plane. Also, the column is slender, that is, its length is much larger than its lateral dimensions and the cross-section and longitudinal displacements are infinitesimal. Only the deformations parallel to the longitudinal direction of the column are considered and physical properties in each cross section can vary from element to element. Finally, the model allows a variation of column geometry along its length and over time and applied loads and boundary conditions can also vary over time.

There seems to be no use in a model that considers rheological properties in the assessment of a column tested under shortterm loading, but the state of coercion imposed on the structure by shrinkage that occurs since casting of the concrete, which produces tensile stresses in the concrete and compressive stresses on the reinforcements, can be considered through this model.

The stress and strain states are iteratively calculated for each increment of time and bending moment and axial force resultants of these stresses are compared to the actual applied loads to assess convergence in each cross section. To ensure the convergence of the iterative search process present in the theoretical model, the compressive strength of concrete and steel stress must consider unlimited. Since the theoretical model is applicable to the verification of structures in the service limit state, the stresses are less than limit of the strength of the materials, and therefore the non-verification of the stress values is acceptable. However, for ultimate limit state verification, materials stress checking with strength limits is paramount. More details on the theoretical model and equations necessary for its implementation can be obtained in Pereira et al. (2013) [20].

Since the proposed model does not consider the effects of geometric nonlinearities, a simplified alternative to consider these effects was used: the displacements of the previous step were used to determine an increment of the bending moment corresponding to the product of the applied force by the second-order eccentricity.
\end{abstract}




\section{Numerical ANAlysis Using the Finite Element Method}

I $\mathrm{n}$ the present study, numerical models were developed in the ANSYS Mechanical APDL software [14]. Three types of elements were used to represent the specimens. For concrete modelling, the SOLID65 element, available in the element library, was used. This element is volumetric and has eight nodes with three degrees of freedom per node, corresponding to the displacements in three directions. The representation of the reinforcement bars was made in a discrete manner, by means of truss elements (LINK180), which share nodes of the concrete volume mesh, enabling consideration of a perfect adherence between the two materials. Finally, rigid elements (MPC184) were used for the application of the eccentric load instead of direct modelling of the concrete consoles. These elements are intended to connect the nodes of the upper face of the column to the load application node, positioned at a distance from the axis of the column equal to the eccentricity adopted in the tests. The elements used are shown in Fig. 4. In this figure, some of the volumetric elements corresponding to the concrete are omitted to allow visualization of the reinforcements.

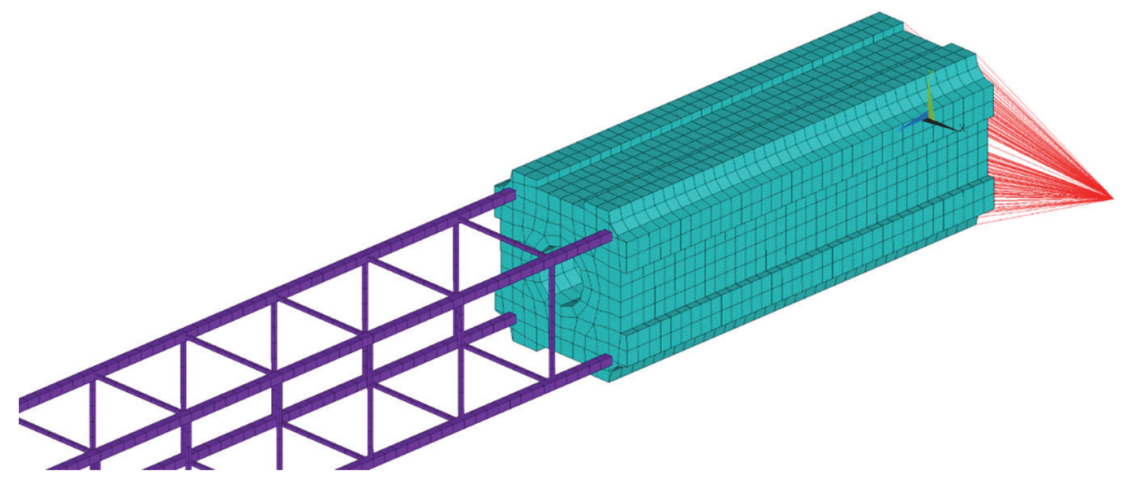

Figure 4: Elements used in the numerical modelling of the column. SOLID65 in green, LINK180 in purple and MPC184 in red.

Due to the symmetry of the problem, only one quarter of the column was modelled for each analysis, which allowed considerable gain in processing time. In addition, due to the difficulty of mesh generation, small simplifications were adopted in the cross section, as shown in Fig. 5.

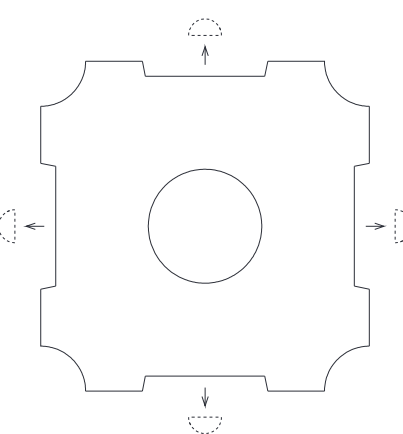

Figure 5: Simplified cross section used in the numerical modelling.

A mesh with a characteristic dimension equal to $20 \mathrm{~mm}$ was adopted and generated freely by the program. Meshes with smaller dimensions were evaluated, however the results obtained with the $20 \mathrm{~mm}$ mesh were deemed satisfactory, as will be seen in the next section.

For modelling of the materials, the stress-strain relationship presented in the ABNT NBR 6118:2014 [3] (a parabolarectangle diagram), with a compressive strength of $33.5 \mathrm{MPa}$ was adopted for the concrete. The tensile strength of the concrete was calculated according to this standard and the adopted value was equal to $3.12 \mathrm{MPa}$, since there was no tensile test for the concrete. The Willam \& Warnke criterion was used to model material behaviour. Open and closed crack shear coefficients were adopted as 0.6 and 0.9 respectively, as proposed by Contamine et al. (2011) [21]. Steel was modelled as elastic, perfectly plastic, with a yield stress of $500 \mathrm{MPa}$ and a Young's modulus of $200 \mathrm{GPa}$. 
Solution was performed considering both physical and geometric nonlinearities, using displacement control, with initial displacement increments of $0.05 \mathrm{~mm}$, but these increments were automatically changed by the software to accelerate the solution in each model.

\section{RESULTS AND DISCUSSION}

T ig. 6 to 9 present the vertical load $v$ s. displacement (parallel to the longitudinal direction of the column) curves obtained with each different methodology. The columns also had their strength calculated according to the prescriptions of the EN 1992-1-1:2004 [22].

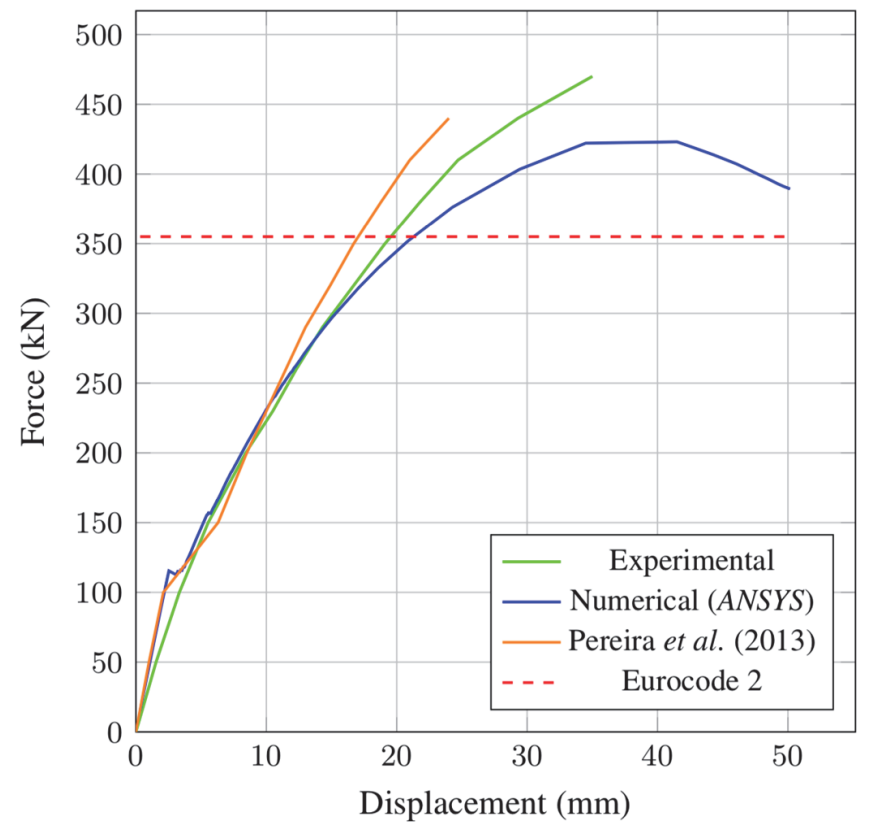

Figure 6: Load vs. displacement curves obtained with the four different methodologies for model E1.

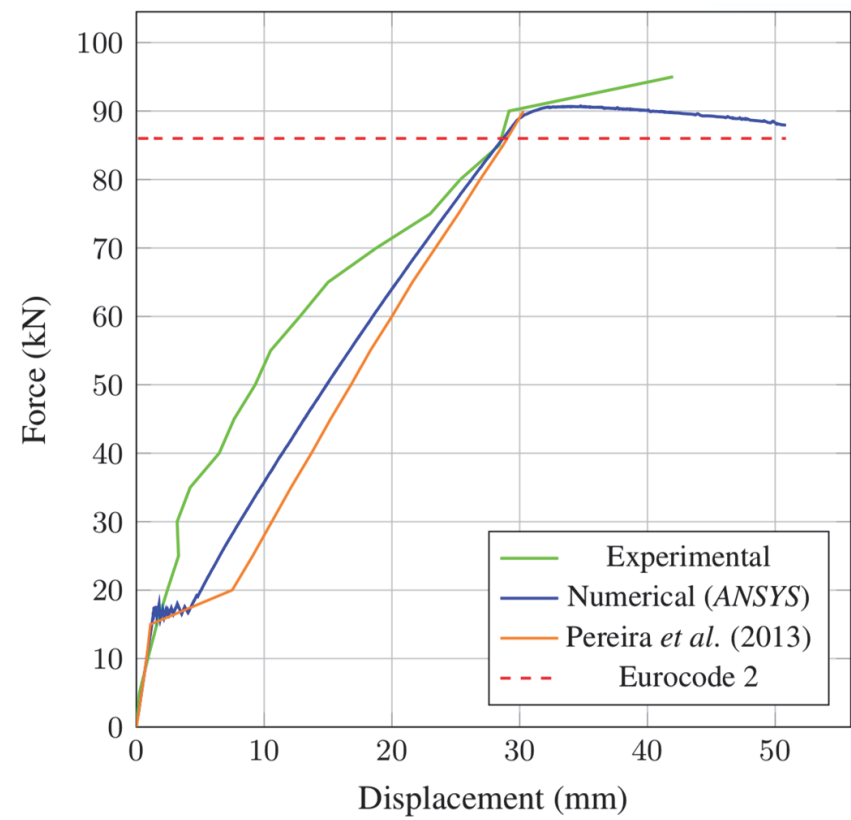

Figure 7: Load vs. displacement curves obtained with the four different methodologies for model E2.

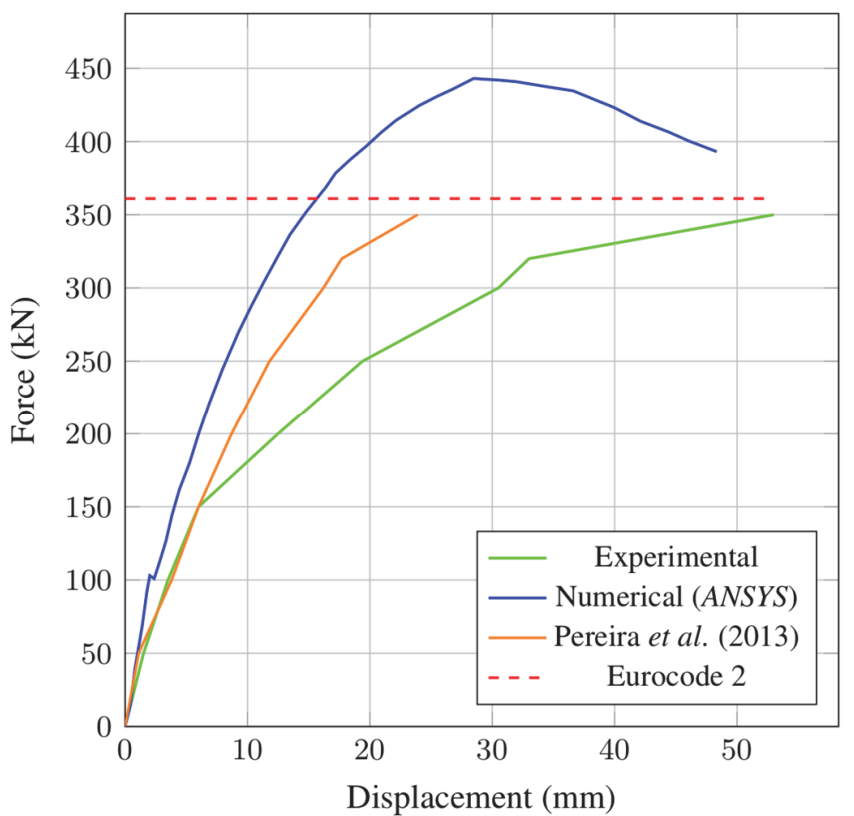

Figure 8: Load vs. displacement curves obtained with the four different methodologies for model E3. 


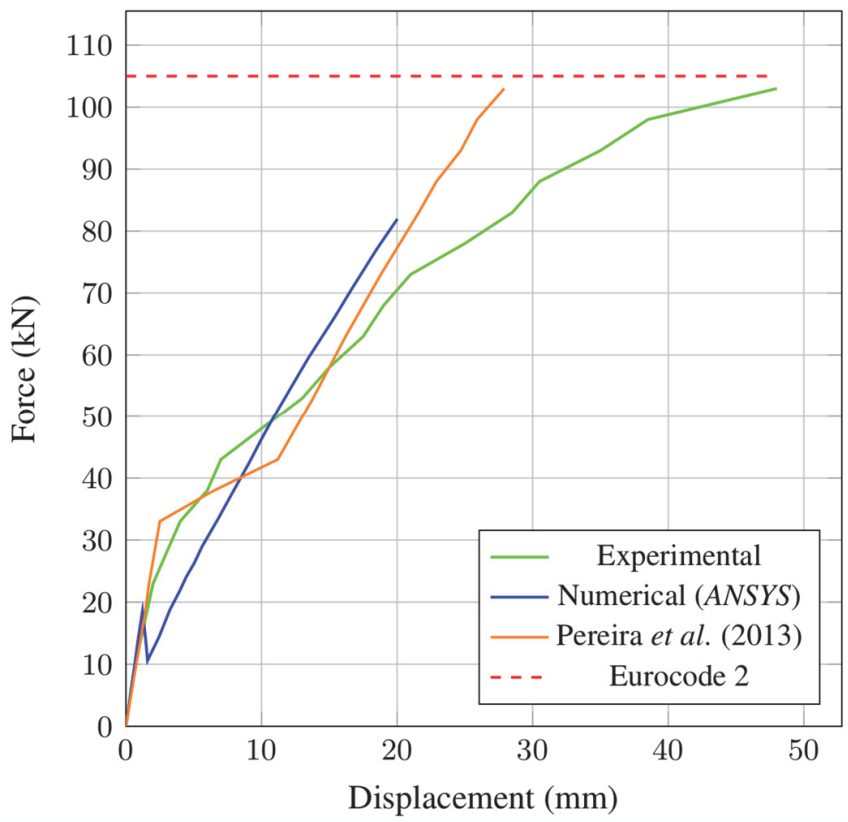

Figure 9: Load vs. displacement curves obtained with the four different methodologies for model E4.

It was possible to note that the numerical and theoretical models showed similar behaviour throughout the analyses, with small differences after the occurrence of cracking. It should be highlighted that in most cases, there is a formation of a plateau in the load-displacement curves both for the numerical and analytical assessments, corresponding to the beginning of cracking. This behaviour, although theoretically expected, was not observed in the experimental analysis.

For the theoretical and numerical models of specimen E1, an initial overestimation of stiffness (up to about $110 \mathrm{kN}$ ) was observed until the beginning of cracking. From this point on, a sharp decrease in stiffness was observed. All models, except for model E3, which presented an excessive estimation of the stiffness, behaved similarly to the experimental model up to the serviceability limit state, estimated as the ultimate strength divided by 1.4. After this limit, a difference between predictions was observed. For the theoretical model, this distance can be caused by the inability of the formulation of analysing concrete with severe cracking, in ultimate-limit state. For the numerical models, after the serviceability limit, excessive loss of stiffness was observed due to the amplification of stresses caused by geometric nonlinearity, together with generalized cracking. Numerical models for tests E3 and E4 were not able to predict adequately the strength of the column. While model E3 led to an overestimation of strength, model E4 was unable to reach convergence due to excessive cracking. For the theoretical and numerical models of specimen E2, a coincidence in behaviours was observed up to the beginning of cracking. After this point, both models presented loss of stiffness higher than the one presented on the experimental model, with the behaviour described by an almost straight line. At this point, it was observed that a considerable part of the section was cracked, and only the reinforcements resisted the tensile stress in that portion of the column. Even with loss of stiffness, both models presented a behaviour close to that of the experimental model up to the serviceability limit state 70 $\mathrm{kN})$. For this column, the strength obtained in the numerical model presented a difference of less than $5 \%$ of the one obtained experimentally.

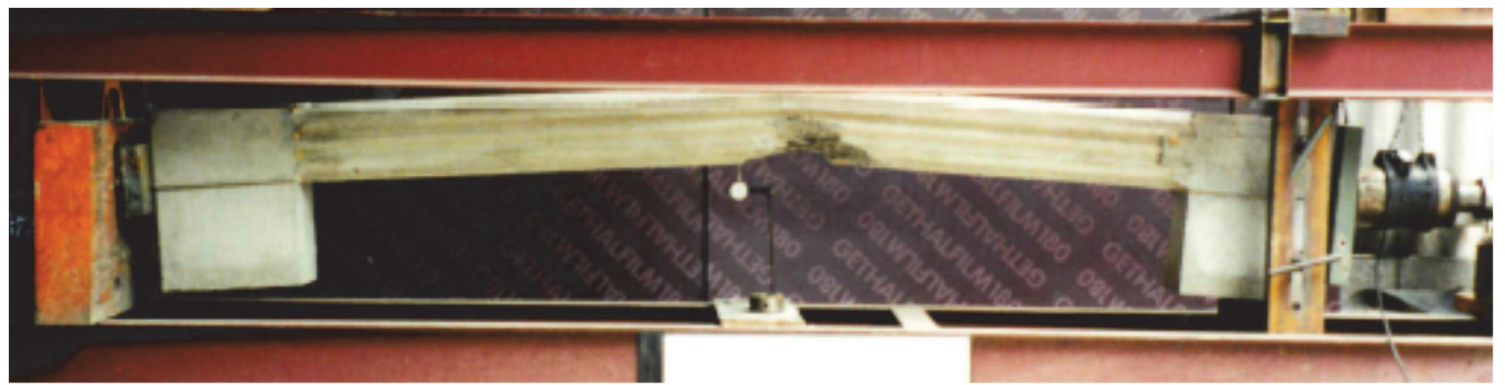

Figure 10: Specimen E1 at the time of rupture in the experimental testing. 
Regarding the predictions of the Eurocode 2, the strength of the column was very close to the one obtained experimentally in most tests, with only an underestimation of $28 \%$ in model E1. All other models presented less than $15 \%$ of deviation. This indicates that current standardized procedures are also applicable to elements with unusual cross-section.

Figs. 10 and 11 present specimen E1 at the time of rupture in the experimental and numerical models.

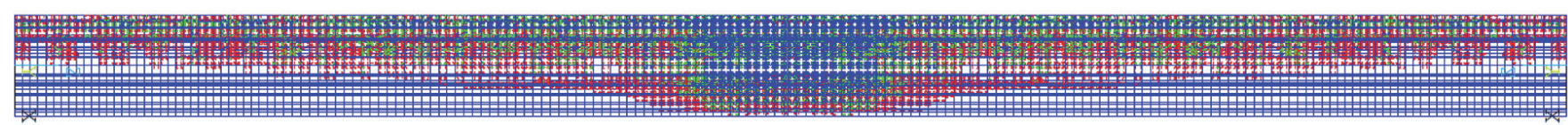

Figure 11: Crack pattern in specimen E1 numerically obtained for the time of rupture.

\section{CONCLUSIONS}

7 he behaviour of a precast reinforced concrete column for use in a modular housing project was evaluated according to different methodologies. To validate these methods, an experimental program was developed considering four different load eccentricities.

The first proposed methodology was developed in accordance with the code requirements of the Brazilian ABNT NBR 6118:2014 standard [3] and is intended to describe the serviceability behaviour of structural reticulated reinforced concrete elements. The second methodology was based on finite element numerical models considering both physical and geometric nonlinearities. It was verified that, in general, both methodologies presented good correlation with experimental results regarding global serviceability behaviour.

For the theoretical and numerical models of specimen E1, an overestimation of the initial stiffness in relation to the test behaviour was observed. From this point on, a sharp decrease in stiffness was noted. Both models behaved similarly to the experimental model until the serviceability limit state and, after this limit, a difference between values was observed. This was expected since the theoretical model does not present an adequate formulation for the evaluation of ultimate limit states. The numerical model of specimen E1 showed a strength about 10\% lower than the experimental one and for specimen E2, this difference was $5 \%$ smaller. Differences of this order of magnitude can be considered appropriate mainly due to the complexities involved in this analysis, together with the uncertainties involved in the tests' measurements.

Numerical analyses for specimens E3 and E4, on the other hand, did not present such good correlation with experimental results, especially when ultimate limit state was analysed. While the numerical model for test E3 resulted in a high overestimation of the strength, model E4 presented a convergence problem with low ultimate load.

Strength calculations according to Eurocode 2 led to good agreement with the experimental results, indicating that these standards may be adequately used to predict the load capacity of columns with unusual cross-sections.

The models here proposed are feasible for the behaviour prediction of precast reinforced columns, and it is possible to extend the application of these methodologies to other practical situations such as bending of beams and slabs.

Although the theoretical methodology proposed does not have such a high degree of sophistication compared with the Finite Element numerical model, a good correlation of results was observed, especially for lower loading levels expected in a serviceability situation. Therefore, this formulation is an alternative to the use of generic finite element commercial software, which require large initial investment and extensive operator training, in addition to presenting numerical convergence problems that are difficult to solve.

\section{ACKNOWLEDGEMENTS}

he authors would like to thank the funding agencies CAPES and CNPq for the support received and PRECON Industrial for the supply of materials, facilities and labour to conduct the tests.

\section{REFERENCES}

[1] El Debs, M.K. (2000). Concreto Pré-Moldado: Fundamentos e Aplicações, São Paulo, Escola de Engenharia de São Carlos. 
[2] Associação Brasileira de Normas Técnicas. (2017). NBR 9062 - Projeto e execução de estruturas de concreto prémoldado, Rio de Janeiro.

[3] Associação Brasileira de Normas Técnicas. (2014). NBR 6118 - Projeto de Estruturas de Concreto - Procedimento, Rio de Janeiro.

[4] Feng, D., Wang, Z., Wu, G. (2019). Progressive collapse performance analysis of precast reinforced concrete structures, Struct. Des. Tall Spec. Build., 28(5), pp. e1588, DOI: 10.1002/tal.1588.

[5] Li, J., Hao, H., Wu, C. (2017). Numerical study of precast segmental column under blast loads, Eng. Struct., 134, pp. 125-137, DOI: 10.1016/j.engstruct.2016.12.028.

[6] Ghayeb, H.H., Razak, H.A., Sulong, N.H.R. (2017). Development and testing of hybrid precast concrete beam-tocolumn connections under cyclic loading, Constr. Build. Mater., 151, pp. 258-278, DOI: 10.1016/j.conbuildmat.2017.06.073.

[7] Wibowo, A., Wilson, J., Lam, N., Gad, E. (2009). Modelling Precast Reinforced Concrete Columns and Comparison with Results from Field Testings. The First International Conference on computational Technologies in Concrete Structures, Korea, 24-27 May.

[8] Chen, A.C.T., Chen, W.F.(1973). Constitutive relations of concrete and punch-indentation problems. Fritz Engineering Laboratory Report No. 370.11. Lehigh University Bethlehem, Pennsylvania.

[9] Chen, A.C.T., Chen, W.F. (1975). Constitutive relations for concrete. Journal of the Engineering Mechanics Division, ASCE, 101(4), pp.465-481.

[10] Willam, K.J., Warnke, E.P. (1975). Constitutive models for the triaxial behavior of concrete, Proceedings of the International Association of Bridge Structures, 19, pp.1-30.

[11] Ottosen, N. S. (1977). A failure criterion for concrete. Journal of Engineering Mechanics Division, ASCE, v. 103, n.4, p.527-535.

[12] Hsieh, S. S., Ting, E. C., Chen, W.F. (1982) A Plastic-Fracture Model for Concrete. International Journal of Solids and Structures, 18(3), pp.181-197.

[13] Boswell, L. F., Chen, Z. (1987). General Failure Criterion for Plain Concrete. International Journal of Solids and Structures, 23(5), pp.621-630.

[14] ANSYS version 18.2, Program Documentation: Theory Manual.

[15] Barbosa, A.F., Ribeiro, G.O. (1998). Analysis of reinforced concrete structures using ANSYS nonlinear concrete model. Computational Mechanics. CIMNE. Spain, Barcelona.

[16] Wolanski, A.J.B.S. (2004). Flexural Behavior of Reinforced and Prestressed Concrete Beams Using Finite Element Analysis, M.S. Dissertation, Marquette University, Milwaukee, Wisconsin, USA.

[17] Queiroz, G., Carvalho, H., Rodrigues, F., Pfeil, M. (2014). Estimation of friction contribution in the behavior of steelconcrete composite beams with flexible shear connectors. REM: Esc. Minas, Ouro Preto, 67(3), pp.253-258.

[18] Lazzari, P. M., Filho, A.C., Lazzari, B.M., Pacheco, A.R. (2017). Structural analysis of a prestressed segmented girder using contact elements in ANSYS. Computers \& Concrete, 20(3).

[19] Lazzari, B. M., Filho, A. C., Lazzari, P.M., Pacheco, A.R. (2017). Using element-embedded rebar model in ANSYS for the study of reinforced and prestressed concrete structures. Computers \& Concrete, 19(4).

[20] Pereira, S.R., Calixto, J. M, Bortone, T.P. (2013). Análise numérica de lajes alveolares protendidas submetidas a carregamentos de longa duração. Revista Ibracon de Estruturas e Materiais. 6(4), pp.613-622.

[21] Contamine, R., Si-Larbi, A., Than, N.Q., Hamelin, P. (2011). Numerical modeling of reinforced concrete beams under shear stress with and without external textile-reinforced concrete reinforcement, J. Reinf. Plast. Compos., 30(15), pp. 1293-303, DOI: 10.1177/0731684411420189.

[22] Comité Européen de Normalisation. (2004) EN 1992-1-1:2004. Design of Concrete Structures - Part 1-1: General rules and rules for buildings. Brussels, Comité Européen de Normalisation. 